Running head: Complex Dynamic Systems

\title{
A Complex Dynamic Systems Perspective on Identity and Its Development: The Dynamic Systems Model of Role Identity
}

\author{
Avi Kaplan \\ Psychological Studies in Education \\ College of Education \\ Temple University \\ +267-254-7129 \\ akaplan@temple.edu \\ Joanna K. Garner \\ Center for Educational Partnerships \\ Old Dominion University \\ $+757-683-5448$ \\ jkgarner@odu.edu
}

Manuscript submitted for a Special Issue of Developmental Psychology:

Identity Development Process and Content: Toward an Integrated and Contextualized Science of Identity

\section{Accepted March 10, 2017}

(C) 2017, American Psychological Association. This paper is not the copy of record and may not exactly replicate the final, authoritative version of the article. Please do not copy or cite without authors permission. The final article will be available, upon publication, via its DOI: 10.1037/dev0000339

Please address all correspondence regarding this manuscript to Avi Kaplan at: akaplan@temple.edu 


\title{
A Complex Dynamic Systems Perspective on Identity and Its Development: The DyNAMiC Systems Model OF Role IDENTITY
}

\begin{abstract}
Current prominent models of identity face challenges in bridging across divergent perspectives and dimensions such as personal or social-collective, conscious or unconscious, and epigenetic or discursive-relational, and affording pursuit of research questions in ways that allow integrative answers. We address the special issue's goals by describing a model that provides a coherent theoretical perspective on the integrative nature of identity and its developmental mechanisms. Adopting the contextual social role as a primary unit-of-analysis, the Dynamic Systems Model of Role Identity (DSMRI) conceptualizes role-identity as a Complex Dynamic System (CDS) anchored in action that comprises the actor's ontological and epistemological beliefs, purpose and goals, self-perceptions and self-definitions, and perceived action possibilities in the role. These system components are conceptualized as interdependent, and identity development is viewed as emergent, continuous, non-linear, contextualized, and given to influences from within and without the system. The role-identity itself constitutes an element within a multi-level hierarchy, which at the unit-of-analysis of the individual reflects a CDS that comprises the person's multiple roleidentities. Identity development involves the formation and restructuring of relations within and among role identities through intra- and inter-personal processes, which are mediated by sociocognitive and cultural means, and framed by the context as well as by individual dispositions. The DSMRI provides a framework to conceptualize and investigate the nature of the identity system, its development, and the relationship between identity development and psychological functioning at different units-of-analysis, among people with different characteristics, across different developmental stages and contexts, and using quantitative and qualitative methodologies.
\end{abstract}

Keywords: Identity, Complex Dynamic Systems, Role, Motivation 


\section{A Complex Dynamic Systems Perspective on Identity and Its Development}

Divergent assumptions among varied theoretical perspectives on identity have framed decades-old debates about identity's nature: stable or malleable, personal or social-collective, individual or cultural, conscious or unconscious; its development epigenetic or discursiverelational (Côté \& Levine, 2002; Gergen, 1991; Holland \& Lachicotte, 2007). Yet, increasingly, researchers have been drawing links across perspectives to better capture the nature of identityrelated phenomena (Schwartz, Luyckx, \& Vignoles, 2011). Indeed, rather than "whether-or," identity phenomena manifest both sides of apparent dichotomies - they are stable and malleable, personal and social-collective, conscious and unconscious, guided by individual dispositions and given to situational influences, and reflective of an integration of epigenetic and intra-personal and relational mechanisms that are mediated by historical-cultural contexts (Vignoles, Schwartz, \& Luyckx, 2011). However, current prominent models of identity face challenges in bridging across such dimensions and affording pursuit of questions such as why, when, and how does identity develop, in ways that allow integrative answers. In the current paper, we address the special issue's goals by describing a model based on assumptions of Complex Dynamic Systems (CDS) (Guastelo, Koopmans, \& Pincus, 2009; Kunnen \& Van Geert, 2012) that provides a coherent theoretical perspective for conceptualizing, investigating, and intervening in the integrative nature of identity and its developmental mechanisms. We begin the paper with a brief review of current challenges in theories of identity and its development, continue with a review of assumptions and concepts of complex dynamic systems that can address those challenges, follow with a detailed description of the Dynamic Systems Model of Role Identity (DSMRI) and how it captures insights about identity and its development from different perspectives, then provide several brief examples of the model's application in research and intervention projects on role identity and its change. We conclude with the need for further theoretical development and research.

\section{Challenges in Conceptualizing Identity and Its Development}

Erikson's (1968) highly complex psychosocial conception of identity as "a process 'located' in the core of the individual and yet also in the core of his communal culture" (p. 22) that 
involves a "conscious sense of individual uniqueness...an unconscious striving for a continuity of experience...[as well as the] solidarity with a group's ideals" (p. 208) spurred a plethora of definitions, models, and research projects that aimed to be more precise but ended up emphasizing different aspects of the diverse phenomena that can be categorized under the term "identity" (Schwartz et al., 2011). Scholars adopting a variety of psychological, sociological, and anthropological disciplinary perspectives, and pursuing questions about varied topics spanning individual development and motivation, interpersonal relationships, teams' performance, intergroup relations, and ethnic and gender demographic trends in society, have employed the concept of identity under multitude interpretations of the question: "who are you?" (Vignoles et al., 2011, p. 2). In a comprehensive summary of the different literatures on identity, Vignoles, Schwartz, and Luyckx (2011) pointed to four central thematic tensions that concern the core definitional tenets of identity, its formation, and its investigation across perspectives: "1. Is identity viewed primarily as a personal, relational, or collective phenomenon? 2. Is identity viewed as relatively stable, or as fluid and constantly changing? 3. Is identity viewed as discovered, personally constructed, or socially constructed? 4 . Should identity be researched using quantitative or qualitative methods?” (p. 8). These four overarching tensions house multiple more nuanced differences in emphases, including whether identity is viewed primarily as conscious or implicit; is identity viewed primarily in terms of its content (e.g., commitments), its process of formation (e.g., identity styles), or its structure (e.g., degree of integration); and, is identity formation and development viewed primarily to follow epigenetics or discursive practices. Vignoles et al. (2011) noted that different approaches and emphases in conceptualizing and investigating identity have unique strengths and have contributed to knowledge about various identity phenomena, and argued that debates that aim to resolve dichotomous tensions to one or another side are unproductive since identity phenomena are not either-or, but manifest all those emphases, with different salience among different actors, at different units-of-analysis, and within different socialcultural contexts. Such an understanding calls for "an integrative perspective that brings together 
the strengths of these seemingly contrasting theoretical and methodological approaches without losing sight of the unique contributions that each of these approaches can make" (p. 12).

However, despite some progress in integrating across certain perspectives, the literature still lacks a conceptualization of identity that would allow an effective integration. One main requirement for the generation of integrative models of identity that bridge diverse disciplinary lines is a paradigm that would allow to coherently conceptualize processes across units-of-analysis and seemingly dichotomous divides such as stable-malleable, dispositional-contextual, consciousimplicit, intrapersonal-relational; a paradigm that allows for the conceptualization and modeling of gradual change as well as fluctuations, linear effects as well as nonlinear and disproportional effects, and unidirectional as well as multidirectional and reciprocal relations. We argue that one such paradigm is the Complex Dynamic Systems (CDS) approach. In the next section, we provide a brief explication of assumptions underlying CDS and the similar framework of RelationalDevelopmental Systems, before discussing its application to conceptualizing and investigating identity and its development.

\section{The Complex Dynamic Systems Approach}

The Complex Dynamic Systems (CDS) approach is a scientific paradigm that has been developing in the natural and social sciences during the past several decades and that views diverse phenomena-including, for example, the weather, the brain, ecosystems, the economy, locomotion, language, organizations, families, education, culture, personality, emotion, cognition, motivation, development - as complex dynamic systems: networks of interdependent elements whose continuous, iterative, interaction give rise to the system's behavior (Bar-Yam, 1992; Guastello \& Leibovitch, 2009; Waldrop, 1992). Unlike "simple" systems, which comprise few elements that connect to each other in a linear and non-variable (i.e., deterministic) fashion (e.g., thermostat), or even "complicated" systems, which comprise many elements that connect to each other in a linear and non-variable manner (e.g., airplane), the connections among the elements of a “complex" system (e.g., an ecological niche) are reciprocal and interdependent, so that change in any one element will reverberate throughout the system. While simple systems can be studied by 
adding up characteristics of their unique elements and their connections, the interdependence of elements across the complex dynamic system means that such systems cannot be reduced to their components and must be studied as whole. In addition, while the behavior of simple (e.g., car brakes) and complicated (e.g., car) systems is highly predictable, the behavior of a complex system (e.g., the driver) is commonly nonlinear and much less predictable. Thus, the properties and behavior of a complex system are a function of its elements as well as of their interdependent relationships, which involve "varying types and strengths of interconnections and complex patterns of positive (deviation amplifying) and negative (deviation reducing) feedback, which defy simple cause-effect logic" (Rowland, 2007, p. 10). Furthermore, unlike many simple or complicated systems that can reach equilibrium and stasis, most complex systems are in perpetual movement and, hence, are in a continuous state of "becoming," and their behavior continuously emerging.

Such meta-theoretical assumptions of the CDS approach differ markedly from the traditional deterministic and linear "Newtonian" approach common in psychological research. However, the CDS assumptions are not foreign to developmental science (Witherington, 2015), and are shared by the Relational-Developmental Systems paradigm (Lerner, 2012; Overton, 2013). The Relational-Developmental Systems paradigm came to address similar challenges to those noted above in regards to broad developmental phenomena. Overton (2013) noted the increased recognition of the futility of dichotomous debates in developmental psychology, such as nature vs. nurture, evolution vs. individuals' development as the unit-of-analysis, or individual attributes vs. socio-cultural influences on development, and the need for integrative approaches that would bridge across such divides. The Relational-Developmental Systems paradigm provides such an approach by specifying assumptions regarding developmental phenomena that are akin to those of CDS (Witherington, 2015). Drawing on a Relationist worldview, which specifies ontological assumptions that integrate rather than split process and substance into a dialectical and emergent view of phenomena, and epistemological assumptions that involve holistic knowledge of such phenomena, the Relational-Developmental Systems paradigm views developmental phenomena 
and their investigation according to principles derived from Holism. Holism is a general epistemological principle that views objects and events as receiving their meaning from their relations with each other and from the context in which they are embedded: "Wholes define parts and parts define wholes" (p. 98). A holistic scientific approach to phenomena highlights the epistemological benefits of the complementary principles of identifying different elements of a system as mutually constituting each other ("The Identity of Opposites"), yet didactically identifying these elements as different from each other to allow anchors for analysis of the system ("The Opposites of Identity"), but only in order to follow by conceptualizing them as interdependent parts of a larger whole ("The Synthesis of Wholes") (Overton, 2013, p. 98). The application of these relational ontological and epistemological assumptions involves viewing causality within developmental phenomena as multi-directional or circular, with all individual and contextual aspects existing in mutually influential relations that render "the potential for plasticity...of intraindividual change... a hallmark" of the approach (p. 102). Living organisms, according to this approach are "active agents, that is...relational, spontaneously active, complex adaptive systems, that are self-creating (i.e., enactive; autopoetic), self-organizing (i.e., process according to which higher level system organization arises solely from the co-action of lowerlevel components of the system), and self-regulating" (p. 102). According to the RelationalDevelopmental Systems perspective, the development process is non-linear ("inputs are not proportional to outputs," p. 102), irreversible, and emergent, with "the system...being completely contextualized and situated" (p. 102). System change leads to increased complexity, with new systemic forms exhibiting "novel features that cannot be reduced to (i.e., completely explained by) or predicted from earlier forms" (p. 103). Another core concept of the Relational-Developmental Systems paradigm is that it is "the source of action" (p. 103), which constitutes the mechanism of development through its instantiation of the relations between the system and its environment.

Importantly, whereas the Relational-Developmental Systems and the CDS paradigms provide a generally coherent set of ontological and epistemological principles with which to conceptualize and study developmental phenomena, there is diversity of metatheoretical 
perspectives within these paradigms. Of particular relevance to our model of identity is a distinction between two CDS perspectives that have been labeled Radical-Contextualist (or, the Bloomington approach) and Organicismic-contextualist (or, the Gronningen approach) (Kunnen \& van Geert, 2012; Witherington, 2007, 2015). Briefly, Contextualism (e.g., Thelen \& Smith, 1998) focuses on foundational empirical actions of agents in real time, and considers only bottom-up emergent patterns, that begin at the level of those specific acts and self-organize to manifest higher order patterns, as legitimate explanation of developmental phenomena. In comparison, Organicism (e.g., Kunnen, 2012) considers also systemic phenomena of higher order than specific acts, such as meanings, beliefs, goals, and identities as legitimate explanatory constructs of developmental phenomena, thus allowing the conceptualization of both bottom-up and top-down causal paths within a dynamic system. Such higher order organizational levels in the dynamic system, which emerge in a bottom-up causal path from the self-organization of their lower-level elements (e.g., sensations emerging into a perception; concrete experiences emerging into a general belief), simultaneously provide affordances and constraints in the continuous self-organization of the system in top-down causal paths that manifest also in patterns of lower-level structures (e.g., a perception framing sensations; a belief framing concrete experiences) (Witherington, 2011). Drawing on the prevalent identity literature, our conceptualization considers both specific actions and higher-order psychosocial, social-cognitive, and social-cultural identity concepts as influencing identity phenomena through multi-directional and circular bottom-up and top-down causal influences, thus aligning our perspective with ontological emergence (Witherington, 2011), and our identity model with assumptions of the Organismic approach.

Across CDS perspectives, theorists and researchers had to contend with the inadequacy of the prevalent deterministic cause-effect relations and linear statistics to capture conceptual and empirical complex, nonlinear, and emergent phenomena. During the past several decades, complexity scientists have been articulating new concepts and mechanisms to conceptualize, study, characterize, and model the nature of complex dynamic systems, capture their regularities, and anticipate their behavior (Guastello \& Leibovitch, 2009). A comprehensive review of the 
variety of CDS concepts is beyond the scope of this paper (see Guastello, Koopmans \& Pincus, 2009; Kunnen, 2012); therefore, we will focus on a set of concepts that are particularly relevant to our application of CDS to identity—specifically, iterative change, attractors and repellors, control parameters, and self-similarity and fractals (Guastello \& Leibovitch, 2009; Kunnen \& van Geert, 2012; Witherington, 2007).

\section{The Iterative Nature of a Complex System Change}

The assumption that the change of a complex dynamic system occurs as an iterative process implies that any state of the system emerges on the basis of its previous state, and will provide a basis for its next state. Similar to the input and output of "recursive equations" (e.g., $\mathrm{y}_{\mathrm{t}+1}=f\left[\mathrm{y}_{\mathrm{t}}\right]$ ), each iteration of the system serves as an output of its previous iteration and an input for its next iteration (van Geert \& Steenbeek, 2005). Thus, whereas a complex dynamic system is in a continuous state of emergence, new states that involve only little change in the system's elements and their relations would manifest as stability of the system. Such is likely to be the case

in complex dynamic systems with strongly established relations among elements. Future iterations of such systems will activate those connections and manifest in very similar, seemingly stable, system behavior. Importantly, however, the continuous emergence also implies the ever-present potential for more significant change, even in the most seemingly stable systems. Particularly because of the interdependence among the systems' elements, momentary influences on different elements, some of which may seem minor, would reverberate throughout the system and could, under certain conditions, lead to sudden radical change in the system's next iterations (i.e., a "butterfly effect").

\section{Attractors and Repellors}

In the possible conceptual space of states that a complex dynamic system can occupy, there are certain states in which the system would be more stable than others. These states are called attractors. When connections between the system's central elements provide positive feedback loops to each other, the triggering of one element positively activates the others resulting with internal dynamics of the system's iterative change towards an attractor state. External forces on 
the system could also influence its change towards a more stable attractor state. Thus, an attractor state reflects relative equilibrium of influences between continuously operating internal and external influences, with the iterative activation of the connections between the system's elements and with its context manifesting a pattern of stability in its behavior. Importantly, some attractor states would reflect a stronger relative equilibrium and thus would manifest more stability in the system's behavior than would other states.

In contrast, there are states of the system that are highly unstable and which the system tends to self-organize away from. These are called repellors. Influences in a repellor state involve an integration of internal and external negative feedback loops in which activation of elements negatively activates other elements in ways that produce or enhance tensions, with the continuous activation manifesting in the tendency of the system to self-organize away from the repellors (Kunnen \& van Geert, 2012). As both the system and its context are continuously changing, the state-space of the system's attractors and repellors is also dynamic. However, knowing the characteristics of the type of system, its context, and their evolution, makes it possible to conceptualize a terrain of potential attractors and repellors for a particular complex dynamic system, which may allow anticipation of the system's behavior towards or away from certain states (Guastello \& Leibovitch, 2009).

\section{Control Parameters}

Control parameters provide boundary conditions or behavioral guides for a complex system. Unlike an independent variable in a simple system that influences the system in a determined causal manner, the control parameter in a complex system does not "prescribe or contain the code for the emerging pattern" of the system, but "simply leads the system through the variety of possible patterns or states" (Kelso, 1995, p. 7), like the roles of heat and pressure in the behavior of a physical system (e.g., water being boiled in a pressure cooker). Control parameters do not operate in additive or even interactive fashion, but rather integrate with each other to form combinations that can manifest in non-linear and even chaotic system behavior. For example, whereas control parameters do not relate to the system's behavior in a deterministic manner, a 
control parameter may have critical values that could manifest in the emergence of radical phase transitions of the system's behavior. Control parameters are important for defining the nature of a particular complex dynamic system and can highlight the forces, characteristics, or dimensions that afford and constrain its behavior (Guastello \& Leibovitch, 2009).

\section{Self-Similarity and Fractals}

Self-similarity refers to a characteristic of many complex dynamic systems in which smaller scale elements of the system manifest similar characteristics and principles of behavior to those of larger scale units. Classic examples of self-similarity can be found in natural vegetation, in which organisms contain components that are made of and look like their larger self. Such is the case, for example, with a cauliflower, which is made from florets that look very much like the large cauliflower; or ferns, whose branches are made of small leaves that look remarkably like the branch itself. Many other natural phenomena manifest the self-similarity principle including lightening, waves, shorelines, rivers and their tributaries, snowflakes, and the brain. Fractals are a manifestation of the self-similarity principle and refer to a particular structure that replicates itself horizontally and vertically throughout the system (Guastello \& Leibovitch, 2009). Importantly, the self-similarity of patterns across units-of-analysis is not deterministic, but rather provides a conceptual frame from which to understand processes at the different scales of the system (Koopmans \& Stamovlasis, 2016).

\section{Conceptualizing Identity as a Complex Dynamic System}

Whereas many phenomena manifest complexity characteristics, there are different types of complex systems. Bar-Yam (1992) noted several features that need to be considered when seeking to characterize the nature of a particular system of interest: "Elements (and their number); Interactions (and their strength); Formation/Operation (and their time scales); Diversity/Variability; Environment (and its demands); Activity(ies) (and its[their]objective[s])" (p. 5). Conceptualizing identity as a CDS requires attending to the nature of the identity phenomenathe elements of identity, connections and interactions between identity elements, the iterative process of identity formation, diversity in identity phenomena, the environment within which 
identity forms and identity phenomena occur, and the objective of identity — what is the identity system aiming for.

Following Marcia's (1993) psychosocial identity status model, and the theoretical and empirical literature on identity commitment and exploration, Kunnen and Bosma (Kunnen, 2012; Bosma \& Kunnen, 2001) proposed a complex dynamic model of the change in strength of identity commitment and level of exploration over time during late adolescence. The model focuses on the psychosocial identity system at the unit-of-analysis of the individual adolescent. Kunnen and Bosma conceptualized the change in commitments to be driven by experiences ("events") that can be identity confirming or involve sense of identity conflict. When an event is perceived as identity confirming, positive emotions ensue and commitments are enhanced. In contrast, when an identity conflict occurs in a domain important to the adolescent, strong negative emotions would trigger exploration and, at least initially, commitments decrease. Individuals will differ in their readiness to engage in exploration following conflict depending on their openness to experience.

Based on this conceptualization, Kunnen and Bosma's (Kunnen, 2012) model included the elements of "exploration in breadth," "exploration in depth," "strength of commitment," the "outcome" of the "event," "importance of the domain" to the person, and the personal attribute of "Openness to experience." The model specified the direction and type of connections between these various elements, suggesting that iterations will be triggered by "events" that, depending on the "importance of the domain," would effect either a "confirming-" or a "conflicting-outcome," which respectively would negatively or positively effect "exploration in breadth" that, in turn, would have negative effect on "strength of commitment;" or, when "strength of commitment" is high, and depending on level of "openness to experience," a "conflicting-outcome" would positively effect "exploration in depth," which, in turn, will frame future "outcomes."

Being based on the psychosocial perspective to identity, Kunnen and Bosma's (Kunnen, 2012) dynamic model focuses on the structure and process of adolescents' comprehensive identity formation. They designed the conceptual model specifically to be simulated and modeled quantitatively, and hence included a relatively small set of constructs that were assumed to have 
the same meaning (and metric) across individuals. In comparison, the conceptual model we present here aims at the ambitious goal of incorporating insights about the multiplicity, hierarchy, and cultural-contextual nature of identity phenomena, allowing consideration of diverse identity content in addition to differences and variability in identity structure and process of formation, and being applicable for understanding, investigating, and intervening in identity phenomena across units-of-analysis (e.g., social role, individual, a collective), developmental stages, domains, and social-cultural contexts.

\section{The Dynamic Systems Model of Role Identity (DSMRI)}

Our perspective draws on the Complex Dynamic Systems approach to integrate insights from psychosocial (Erikson, 1968; Marcia, 1993), social-psychological and structural symbolic interactionist (Burke \& Stets, 2009), and social-cultural (Penuel \& Wertsch, 1995; Holland et al., 1998) perspectives on identity and its development. We labeled our model the Dynamic Systems Model of Role Identity (DSMRI). The DSMRI provides a meta-theoretical framework (Overton, 2013) of conceptual principles of the identity system that aim to capture the holistic and rich content, structure, and process of identity and its formation within social-cultural contexts, with anchors in established theoretical constructs.

\section{The Unit-of-Analysis of the Actor}

The focal unit-of-analysis in CDS is the target system and its behavior over time. Conceptualization and research focus on the system's characteristics and on within-system processes. The primacy of the system as the unit-of-analysis comes to address an often unexamined and, at times, erroneous assumption of ergodicity in prevalent social science research - that processes within the person are identical to processes between people (Hamaker, 2012). In much contemporary psychological literature, theories describe processes conceptualized at the unit-of-analysis of the individual (e.g., motivation, learning, identity), but empirical research commonly investigates these processes at the unit-of-analysis of the group, drawing potentially unwarranted interpretations about within-individual processes from analysis of variance between 
people. Thus, it is important to explicitly define the primary unit-of-analysis of the target phenomenon and maintain its consistency in theory and empirical research.

Corresponding with both social psychological and social-cultural perspectives on identity, the foundational unit-of-analysis of our model is the actor's contextualized social role identity: the system that reflects the meaning of occupying a certain social position in a particular socialcultural context (Burke \& Stets, 2009; Holland \& Lachicotte, 2007). Whether the role is formal (e.g., student, athlete, teacher, physician) or informal (e.g., friend, neighbor, passenger), or concerns an actor who is an individual (e.g., a nurse, a soccer player, a researcher) or a collective (e.g., an intensive care team, a soccer team, a research unit), occupying a role identity in a particular social-cultural context provides the actor a frame for interpreting and evaluating experiences and events, and making decisions about action in the role (Burke \& Stets, 2009).

\section{Action as the Systemic Anchor}

The DSMRI conceptualizes the role identity system as constituting a (more or less coherently connected) network of role-specific self-perceptions and self-definitions, assumptions and beliefs, values, goals, emotions, and actions that are held by the actor to be central to who they are in the role. The "objective" of this role identity system is action in the role- behavior and its meaning to the actor (Bruner, 1990) — which is a phenomenon that emerges from and reflects a particular state of the role identity system (Overton, 2013). The action, in turn, represents a systemic event that feeds back and influences future iterations of the role identity system through its manifestation to the self and to others of commitments, or lack-there-of, to certain meanings in the role (e.g., a student's action of deciding to study for an exam over going out with friends, or of choosing a certain college major over others, affirms to the self and to other people a particular kind of a student role identity; Eccles, 2009) ${ }^{1}$.

\section{The Role Identity System Elements}

In specifying the elements of the role identity system, we built on Maehr's (1984; Kaplan \& Maehr, 2002; Maehr \& Braskamp, 1986; Maehr \& McInerney, 2004) Personal Investment Theory to specify four contextually constructed, interdependent, and partially overlapping 
components that are presented in the schematic in Figure 1: (1) ontological and epistemological beliefs relevant to the role; (2) purpose and goals in the role; (3) self-perceptions and selfdefinitions in the role; and (4) perceived action possibilities in the role. Each of these components involves role-related knowledge (e.g., knowledge about the world, knowledge about the self, knowledge of possible behavioral strategies) and role-related affect (e.g., emotions tied to certain assumptions about the world, certain goals, and certain self-perceptions).

Ontological beliefs in the role concern the actor's knowledge held as true regarding the world that is relevant to the role, as well as the emotions tied to this knowledge. A person's ontological beliefs involve knowledge and assumptions about cause and effect in a particular context, whether causes are stable or temporary, controllable or uncontrollable, and internal or external to actors (e.g., the assumption that people have control over their conduct in the context), attributions on the basis of these assumptions (e.g., failure is due to people not taking responsibility), and the emotions that are tied to these assumptions and attributions (e.g., anger at those people) (Weiner, 2012). Epistemological beliefs concern the actor's assumptions about the certainty, complexity, and the credibility of sources of their knowledge about the world, and emotions tied to these assumptions (Hofer \& Pintrich, 2004) (e.g., a student's epistemological beliefs that her knowledge about cause and effect in the school context is uncertain, that such knowledge is complex and resides in teachers, and the sense of anxiety tied to these beliefs).

Purpose and goals refer to the actor's knowledge and endorsement of an overall purpose for their role (e.g., the purpose of a counselor to promote well-being among children, the purpose of a student to demonstrate high ability in school), the more concrete goals, objectives, and aims in the role (e.g., the counselor's goal to improve the quality of social relationships of a particular rejected child, the student's goal to get an A on an upcoming exam), and emotions tied to these purpose and goals (e.g., the counselor's or the student's positive anticipation or anxiety about pursuing their goals). Purpose and goals can differ on many dimensions, including intrinsicextrinsic, individual-social, proximal-distal, specific-global, and self-oriented-other-oriented, with 
consequences to affect and motivation (Locke \& Latham, 2002; Vansteenkiste, Lens, \& Deci, 2006).

Self-perceptions and self-definitions concern the actor's knowledge of their own personal and social attributes and characteristics that they consider relevant when occupying the role, and the emotions tied to these self-perceptions and self-definitions. Central self-perceptions in most roles are the actor's overall self-concept of ability in the role (Hattie, 2014), self-efficacy to pursue particular goals successfully (Bandura, 1997), and the emotions tied to these perceptions. Commonly, the salient self-perceptions and self-definitions in the role also involve the actor's self-categorizations and group memberships that become salient in the context, and the meanings and emotions associated with these categorizations (Turner \& Reynolds, 2011). In addition, this component involves the actor's self-perceptions regarding personal worldview, ideology, and values, interests, personality attributes, or physical characteristics that are deemed relevant for the role in that context, and the emotions that are tied to them.

Finally, perceived action possibilities concern the actor's knowledge and perceptions of behaviors as available to them in the role, particularly as these behaviors pertain to the promotion of purpose and pursuit of goals in the role, and the emotions tied to the use of such behaviors. This component includes declarative behavioral intentions (Fishbein \& Ajzen, 2011) and procedural knowledge of such action possibilities, including particular cognitive and behavioral strategies and the self-regulation of cognition, behavior, emotion, and motivation (Boekaerts, Pintrich \& Zeidner, 2000). Perceived action possibilities exclude those actions that the actor perceives as inappropriate, ineffective, or impossible for them to perform in the role.

\section{Connections Among the System's Elements}

The DSMRI implies that in an aligned role identity system, each component is highly interdependent with the others. Actors who possess an aligned role identity will engage in actions that they perceive as available, appropriate, and effective for pursuit of their goals in light of their beliefs about the nature of the situation and about their own relevant characteristics and attributes within that situation. Importantly, in the DSMRI, each component is a category of constructs 
rather than a single variable, allowing the particular construct that is salient in the component to vary within an actor over time and between different situations (e.g., the role identity of a person engaging in a task may manifest initial high salience of personal interest and low salience of selfefficacy followed by a reversal in the respective salience of these two self-perceptions upon encountering challenge in the task). In addition, the DSMRI applies assumptions of complexity for conceptualizing these four components as constituting a complex dynamic system (Kunnen \& van Geert, 2012) - specifically, assumptions regarding the interdependence of these four components, and hence the irreducibility of the role identity system to any distinct component; the continuous, non-linear, simultaneous, reciprocal, and indeterminate relations among the components, and hence the dynamic, non-linear, and at times chaotic nature of the role identity system behavior and its change; and finally, the embedded nature of the role identity system in other systems, and the reciprocal context-components relations, that render the continuous emergence of the role identity system highly contextualized (Overton, 2013).

Figure 1 presents a schematic of the DSMRI that reflects the reciprocal and partial overlapping interrelations among the four components as well as the central location of action, which conveys that the relations of each component to action cannot be considered independently of other system components. Figure 1 also presents the assumptions that the role identity system is domain-specific (e.g., school, work, family; science, humanities, social science); that it continuously emerges within a socio-cultural context, and thus its components and their relations are mediated by cultural meanings; but, that it is also influenced by the actor's implicit dispositions (e.g., temperament/traits, unconscious motives, repressed emotions, conditioned contingencies).

\section{Facets of the Role Identity System: Content, Structure, and Process}

The DSMRI highlights three aspects of the role identity system: content, structure, and process of formation. Any one of these three aspects can vary within an actor across contexts and over time, as well as characterize different identity systems between actors. 
Content. Variation in the content means difference or change in the amount, kind, and complexity of the knowledge, beliefs, goals, emotions, self-perceptions, and perceived action possibilities in the role. For example, an adolescent's role identity as a student may reflect a more performance-oriented than a learning-oriented content configuration (cf. Dweck, 1999) — two possible conceptual attractor states for the student role identity system - and experience identity changes in content when shifting from one of these content attractors to the other. For example, the student may enter a new mathematics classroom with a role identity that involves the ontological and epistemological beliefs that students learn mathematics best when it is presented to them as facts by knowledgeable sources, that students are not capable of directing their own learning in mathematics, and that ability in mathematics is innate. She may pursue the goal of remembering by heart the information taught in class, and experience positive emotions of satisfaction and pride when she is able to cover all the material when preparing for an exam and do well on closed-item tests. She may construct the self-perception that she is very capable and knowledgeable in mathematics, and hence, she may consider copying and memorizing the teacher's lessons as the most appropriate action possibilities for achieving her goal. In light of these initial beliefs, goals, and self-perceptions, she may not consider collaborative open-ended problem-solving as an appropriate or desirable action possibility. This student's role identity may manifest stability as it iteratively activates these same mutually supportive contents in a classroom context that continuously supports them. However, it could also be that she will have experiences that may trigger changes in this content; for example, readings, peer conversations, or afterschool programs that challenge her ontological and epistemological beliefs about how students learn mathematics, suggesting a more constructivist perspective; or, a substitute teacher who challenges her goals of memorization by emphasizing the goals of creativity in learning and doing mathematics; or, developing personal interest in a particular area of mathematics, like geometry, that assumes salience over her perceived ability in her mathematics-student role identity system. Such challenging new content could serve to trigger tensions within and between components and lead to iterative changes in the salient content within this student's role identity. Possibly, 
exploration of her new epistemological insights, goals of creativity, or personal interest, will enhance the salience of this new content in her role identity, iteratively activate negative feedback loops with other performance-oriented content, and involve some negative emotions and feelings of uncertainty, reflecting increased instability of the role identity system, away from the performance-oriented attractor, and in time, towards a more stable state in another attractor. For example, the new content may activate positive feedback loops with content that is more learningoriented, thus promoting iteratively stronger connections and activation of ontological and epistemological beliefs that knowledge in mathematics is complex and that students learn mathematics also by figuring it out through open-ended problems, goals of creatively and collaborative construction of such knowledge, and positive emotions of satisfaction and pride when engaging creatively in producing meaningful personal learning projects, self-perceptions as interested and motivated learner and a good collaborator, and collaborative problem-based inquiry as the most appropriate action possibility in light of these goals, beliefs and self-perceptions. Iterative shifts towards such a learning-oriented mathematics-student attractor state is going to be more likely when the context-i.e., related systems such as peers, the teacher, parents, and the higher order system of the collective classroom culture - involves content and processes that also support the activation of these identity components.

Importantly, as the example above emphasizes, variability in the content of the role identity manifests not only in changes in level on a particular construct within a component (e.g., endorsing higher or lower beliefs about the malleability of intelligence in mathematics; or higher or lower perceived self-efficacy), but also in the salience of different constructs in the components (e.g., changes in the salience of ontological and epistemological assumptions about the malleability of intelligence relative to assumptions about the nature of knowledge in the subject domain; or in the salience of self-perceptions of efficacy relative to self-perceptions of personal interests). Thus, the DSMRI conceptualizes each component as harboring multiple constructs and dimensions, the salience of which may change for the actor across time and in different situations, or be different between actors in the same situation. Such variation in the content of the role 
identity can explain why an actor may change her perception of the self-relevance of a particular event or the utility of a particular practice following a personally meaningful experience that involved learning new content about the world or herself (Kaplan, Sinai \& Flum, 2014). For example, teachers who are participating in a professional development that aims to encourage adoption of new student-centered pedagogical practices are more likely to endorse the new practices as viable action possibilities and enact them in their classroom practice when these new practices fit within their classroom-based professional role identity — that is, they have knowledge of these practices and perceive them to correspond with the unique system of (likely studentcentered) ontological and epistemological beliefs, purpose and goals, self-perceptions and selfdefinitions, and other perceived actions possibilities that they consider central to who they are as teachers (Kaplan \& Garner, 2016). Teachers, whose role identity system involves (most probably teacher-centered) content that is in tension with the new student-centered practices, are less likely to consider these practices to be viable action possibilities. Therefore, an effective professional development program will attend to the participating teachers' role identities and their change, and engage them in "identity work:" consciously exploring their teacher role identity through learning new content and considering its implications to their ontological and epistemological beliefs; eliciting and prioritizing their teaching purpose and goals; reflecting on their personal values, interests, abilities, and attributes as teachers; experimenting with new practices; and, linking and considering the implications of the learning and experiences to other role identity components, thus creating external and internal forces that influence change in the content of the teacher role identity away from less desirable conceptual attractors (e.g., teacher-centered orientation) towards more desirable attractors (e.g., student-centered orientation).

Structure. Variation in the role identity structure refers to differences in the degree of harmony within the content of the system's components and the degree of alignment between the components. Within components, for example, various goals (e.g., a student's goals regarding mastering the material, maintaining positive peer relationships, and achieving high grades) may be in harmony with each other at a certain time and situation, but may shift to be in conflict and 
involve tension because of change in beliefs about learning, social self-concept, or perceived availability of strategies in the context (Boekaerts, 2010). Across components, for example, a student may feel initial alignment between beliefs about the role of active engagement in learning science, goals of developing knowledge in science, and self-efficacy for inquiry projects, but such alignment may change following an experience that lowers perceived self-efficacy for inquiry projects, which may raise misalignment between the components that would reflect in tension and negative emotions within her science-student role identity system.

The structural aspect of the role identity system also refers to the degree of integration between the target role identity and other central role identities of the actor-a structural aspect that reflects a higher unit-of-analysis of the identity system. Whereas an adolescent may initially experience two central role identities (e.g., student and friend) as unrelated, or even to be in conflict (e.g., goals of being successful as a student and as a friend are perceived as mutually exclusive), change in context (e.g., school, peers) and/or personal exploration of the two roles and their relationship could promote shifts and enhanced concordance and integration between the components in the adolescent's two role identities.

Thus, structural variability in role identity systems may manifest in change to the sense of coherence and commitment that the actor feels towards the role. Lower alignment and increased fragmentation in the role identity structure are likely to be reflected in experiences of uncertainty, ambiguity, or tension. Such uncertainty, ambiguity, or tension reflect an element of instability and could serve a systemic trigger for processes of role identity formation that involve iterative change in salience of elements and in harmonization within components, re-alignment of connections between components, and enhanced integration between the target role identity and other role identities, thus manifesting identity change. Increased harmony, alignment, and integration manifest in enhanced identification with the role and clarity with regard to goals and courses of action. In turn, an aligned role identity, with harmonious, aligned, and integrated connections that are supported by extra-systemic contexts reflects a stable attractor state in which iterations are similar and manifest in role identity stability. 
Process. Variation in the process of role identity formation means that the nature of change in an actor's role identity system may differ along time in the breadth (e.g., number of elements), depth (e.g., magnitude of deliberation on connections of content within and between components), affective intensity, and method of role identity construction process. The foundational processes of role identity formation involve change in content of the role identity components, change in the nature of the structural interrelations within and across components, and the change in the relations of the particular role identity with other central role identities.

Processes of role identity system formation are conceptualized as continuously emerging, but as highly dependent on the history of the identity system, its characteristics, and its context, all of which could vary within an actor along time, as well as differ between actors. One important guiding assumption of the DSMRI follows the psychosocial notion that adaptive identity formation processes aim towards integration and coherence (Erikson, 1968). Thus, the DSMRI assumption is that the role identity system fundamentally self-organizes towards attractor states of increased harmony, alignment, and integration (Kunnen \& van Geert, 2012; Overton, 2013). Importantly, however, depending on the history and state of the role identity system (e.g., fragmented versus aligned), and on systemic internal or external events (e.g., a jarring experience), identity formation processes may vary and manifest also movement towards increased entropy and misalignment (Kunnen \& van Geert, 2012). Variation within actors and differences between actors in identity formation processes may also reflect change in the mediation of control parameters in the socio-cultural context (i.e., cultural tools, norms, values, practices, and modes of social interactions; Holland \& Lachicotte, 2007). Finally, differences between actors in role identity formation processes also reflect differences on dimensions that serve as control parameters of the particular person's role identity system. For example, differences in conscious and unconscious dispositions (e.g., openness to experience, need for cognition, self-worth concerns, creativity, implicit motives, social anxiety) could lead to more or less resistance to change in the role identity, both in general and more specifically towards a particular attractor. 
The self-organization of the role identity system formation occurs within a state-space landscape of conceptual attractors that we conceptualize as comprising prevalent cultural constellations of relatively aligned particular beliefs, goals, self-perceptions, and perceived action possibilities (e.g., a learning-oriented student role identity, a performance-oriented student role identity). Contextual supports (e.g., media images, parent approval) and a history of socialization within socio-cultural contexts involve promote the establishment of positive and negative connections between components within these cultural constellations, provide positive and negative horizontal and vertical feedback loops, with activation of one component triggering the others and promoting the tendency of the role identity system to self-organize towards such attractor states. For example, in the cultural context of Western education systems, the ontological belief that learning takes place through active and meaningful knowledge construction is connected with the goal of active engagement and personal mastery, self-perceptions of selfefficacy for learning and interest and positive emotions of satisfaction (or frustration), and the action possibility of personal inquiry, thus manifesting a cultural attractor state of a learningoriented student role identity (Dweck, 1999). Another Western cultural attractor involves positive connections between the ontological belief that ability in a domain is fixed, the goal of demonstrating ability, self-perceptions of self-efficacy for relative performance and emotions of pride (or anxiety), and the action possibility of social comparison, otherwise labeled a performance-oriented student role identity. In the non-linear, dynamic trajectory towards increased harmony, alignment and integration of a particular student's role identity system in Western education contexts, repeated iterative activation of these respective components would involve the formation of the learning-oriented and performance-oriented student identity as possible attractor states, with activation of one component triggering positive and negative feedback loops that influence the role identity system away from a particular role identity state and towards another in the state-space of cultural attractors. From this perspective, difference in role identity formation processes across socio-cultural contexts reflects, to a large degree, the relative prevalence of attractors and repellors in the cultural state-space for the particular type of role identities (Zusho \& 
Clayton, 2011). Such a cross-contextual difference in the type of role identities and their formation processes also reflects the integrated operation of control parameters within the context—physical, social, and psychological affordances and constraints on the role identity formation process.

Role identity exploration and formation is inevitably shaped and mediated by socialcultural meanings and practices (Penuel \& Wertch, 1995). However, corresponding with the psychosocial perspective (Marcia, 1993), our perspective assigns a central role to the actor's agency in initiating and guiding the role identity formation process through the volitional engagement in identity exploration (Flum \& Kaplan, 2006; Grotevant, 1987). Volitional identity exploration action is an emergent phenomenon of the role identity system that is framed by cultural attractors and repellors, the control parameters of unconscious dispositions and contextual affordances, and internal and external systemic events. Accordingly, variability within an actor, and differences between actors, in role identity formation would manifest also in differences in the level of the actor's agency in identity formation, reflecting different identity formation strategies and styles. Along time and evolution of the identity system, and when transitioning between different contexts, the identity formation process may involve active exploration of beliefs, goals, self-perceptions and definitions, perceived action possibilities and their relations within the role. Alternatively, the actor may construct these components and their interrelations primarily through adopting what is emphasized in the environment, by following the normative example of significant others, or even avoid engaging in agentic identity construction altogether (Berzonsky, 1990). Hence, variability in these processes within an actor over time, and differences in role identity processes between actors, can manifest in differences in the breadth, specificity, and depth of the role identity exploration. Furthermore, in some instances, the actor may focus on exploring a particular component (e.g., contemplating a certain belief, or reflecting on the adequacy of a particular goal, or on a particular relation of a goal and action possibilities) and in another she may engage in a more comprehensive identity exploration process (e.g., an overall exploration of the four components and their relations, negotiation of different sub-roles within the social role, or of components across central role identities around a cross-role dilemma) (Luyckx, Goossens, 
Soenens \& Beyers, 2006). These processes may be cognitively and emotionally intense, or be conducted in a more cursory or superficial manner. Finally, variation within an actor and differences between actors in the identity construction process can manifest in the use of different exploratory and construction strategies that reflect the affordances and constraints in the socialcultural context and the cultural tools that mediate the action (e.g., personal reflection through writing or meditation, social conversations, or experimentation).

\section{Hierarchy, Units-of-Analysis, and Self-Similarity in the Identity System}

While the central module in the DSMRI foregrounds the unit-of-analysis of the social role, the perspective views such social roles as elements in a hierarchical structure of complex dynamic systems that makes up the identity system. In the DSMRI, the hierarchical structure of the identity system manifests the principle of self-similarity, or fractal structure, with each role at different levels and units-of-analysis in the system focusing on action at that unit-of-analysis, comprising ontological and epistemological beliefs, purpose and goals, self-perceptions and self-definitions, and perceived action possibilities, and manifesting similar principles regarding content, structure, and process of identity formation. Figure 2 presents a schematic of this hierarchical-fractal nature of the identity system. The level and unit-of-analysis of the role can range from very situated and specific (i.e., a role that is anchored in a very specific situated act by an individual—e.g., a substitute teacher disciplining a particular disruptive student in a particular moment in a particular lesson and classroom) to broad and cross-situational (i.e., a role that is anchored in a long-term strategic approach by a large collective-e.g., a large organization's strategic approach towards achieving its long-term mission). Each of the role identity's systemic elements and components (i.e., beliefs, goals, self-perceptions, action possibilities, and their associated emotions), structural features, and processes within each level and unit-of-analysis, corresponds to the respective level and unit-of-analysis of the role, and together they underlie the emergence of action at that unit-ofanalysis. The action of a substitute teacher disciplining a student in a particular situation would emerge, most proximally, from the teacher's ontological and epistemological beliefs regarding the student in that particular situation (e.g., confidence that he did it intentionally to challenge her 
authority, tied with anger; and that he will continue, tied with anxiety), her goals in that particular situation (e.g., saving face and establishing her authority), her salient self-perceptions and selfdefinitions in the situation (e.g., being a sub, not having rapport with the students in this situation, low efficacy in handling such a situation, being anxious), and her perceived action possibilities regarding achieving her situated goal in light of her beliefs about the situation and about herself (e.g., sending the student out of the classroom). Similarly, at a different unit-of-analysis, the teacher's consideration of an overall disciplinary approach would be conceptualized, most proximally, as emerging from her overall beliefs about the environments within which she works, her overall purpose and objectives for discipline, her self-definition and self-perceptions regarding capacities and values as a disciplinarian, and her consideration of the strategies that are most likely to promote achievement of her purpose and objectives when disciplining, in light of her beliefs concerning the environments and her self-definitions and self-perceptions.

Thus, social role identities comprise sub-roles as elements (e.g., the sub-roles of Lecture Attendant, Discussion-Group Participant, Lab Experimenter, and Test-Taker serve as elements in the higher-order role of Biology Student), and themselves serve as elements in even higher-order role identity systems (e.g., the social role identities of Biology Student, Dorm Resident, and Student Club Member serve as elements in the Undergraduate Student role identity), all the way in a hierarchy to the person's overarching psychosocial Identity at the individual's unit-of-analysis (e.g., the social roles of Student, Daughter, Sister, Employee, Friend, and Partner constituting elements in the individual's overarching identity; our notation here differentiates Erikson's overarching individual unit-of-analysis by denoting Identity with a capital "I" and the individual's lower-level multiple social-role identities with a small “i”).

In the nested nature of the identity system, more specific role identities serve as elements in broader role identities, with the hierarchy involving circular causality processes-horizontalreciprocal, and vertical (bottom-up and top-down) - that integrate to manifest in the system's continuously iterative evolution. Importantly, degree of complexity varies across levels in the hierarchy, and intra-system, inter-system, horizontal and vertical causal influences do not have 
equivalent roles in the emergence of identity phenomena (Witherington, 2011). These highly complex processes require further conceptualization, investigation, and characterization that reflect the type and nature of the particular identity system — work that has only begun in research using the DSMRI. Still, current identity models and research could provide initial expectations in such characterization. For example, structural and process features among social roles at the overarching individual's Identity unit-of-analysis can be expected to be akin to psychosocial identity statuses and styles (Marcia, 1993). Corresponding with Marcia's identity formation status perspective, the exploration and negotiation among beliefs, goals, self-perceptions, and action possibilities that involved elaborate and system-expansive coherent and integrated connections across central role identities, and which manifested in iterative systemic change towards an attractor state that is characterized by responses to perturbations with flexible system-wide activation, reflect a systemic state that is akin with the status of Identity Achievement. Coherent but less elaborate and less expansive connections among such components across central social roles, which involve the emergence of similar iterative states of the identity system that is due primarily to few strong connections established through strong environmental influences and constitute a strong attractor in which the system is relatively insensitive to perturbations, would reflect a systemic state akin with the status of Foreclosure. Persistent tensions between salient and central social role identities in the system, which manifest in exploration, negotiation, and iterative states that involve loose connections among components in repellor states, but that are also influenced by control parameters that promote self-organization, could reflect a systemic state that is akin with the identity status of Moratorium. Finally, lack of coherence within and across role identities in the system, and iterative states of the identity system that are primarily influenced by environmental forces and relatively frequent perturbations guided by control parameters that promote entropy of the system, may reflect a systemic state akin with the identity status of Diffusion. Concordant with the self-similarity principle, similar structural characterizations of identity achievement, foreclosure, moratorium, and diffusion can be applied to role identities of lower order in the hierarchy (here too we may differentiate identity structures at the overarching 
psychosocial individual level with notation that use capital letters and denoted those of lowerorder role identities with lower case letters). Such an approach to role identity statuses seems compatible with Flum's (1994) characterization of some adolescents' identity formation style as "evolutive," where rather than an all-out exploration of the overarching Identity, the exploration of identifications and commitments takes place gradually, focusing on a certain life domain and roles at a time, while maintaining, at least for the time being, commitments in other domains.

The assumptions about the hierarchical and self-similarity structural nature of the identity system also allow consideration of role identity of collectives such as teams and organizations, with individuals occupying different role identities serving as elements in the role identity of a collective (e.g., nurse, physician, paramedic, and ambulance driver serving as elements in the collective identity of an Intensive Care Team). The richness and harmony of content within components across individuals' roles, the alignment of components across roles, and the degree of integration across the roles (e.g., the degree by which the nurse, physician, paramedic, and driver see eye to eye regarding the goals of their respective roles in the team) could reflect different statuses of the team's identity. Correspondingly, processes of collaborative reflection, consideration, experimentation, and negotiation to align these components and integrate the roles reflect processes akin to identity exploration processes at the unit-of-analysis of the individual's Identity. Applying the DSMRI to conceptualize a collective's action, such as a corporation's overall strategic approach, would call for viewing it as emerging from the corporation's policymaking body's collective ontological and epistemological beliefs about the environment within which the corporation operates, its overall mission and long-term objectives, its self-definition and perceptions regarding its capacities, attributes, and values, and its consideration of the strategies that would most likely promote achievement of the mission and long-term objectives in light of the beliefs concerning the environment and the organization's self-definitions and selfperceptions. Importantly, the assumption of self-similarity of the principles regarding system's content, structure, and process across the hierarchical levels and units-of-analysis of the identity system does not imply determinism or sameness of the specific content, structure, nature of 
processes, or degree of organizational complexity across these systemic levels, thus maintaining the assumption of non-ergodicity within the DSMRI.

\section{Past, Present, and Future Role Identities}

One important feature of the complex dynamic identity system that connects the psychosocial assumption about striving for continuity of experience with the social-psychological structure of multiple role identities is a temporal dimension. In addition to role identities that an actor presently occupies, the identity system includes also role identities for past roles that are no longer occupied, and role identities for future-imagined roles (Markus \& Nurius, 1986). A current high school student's higher-order "Student" role identity includes the past role identities of "middle school student" and "elementary school student," a current role identity of "high school student", and perhaps also a future-imagined role identity of a "college student."

Past role identities provide content and structural bases for the construction of present and future-imagined role identities (Sinai, Tossman \& Kaplan, 2016). Future-imagined role identities constitute sought after (positive future possible selves) and feared (negative future possible selves) that provide self-related goals to achieve and avoid within current role identities (Oyserman, Bybee, \& Terry, 2006). Stereotypical future-imagined positive and negative role identities can serve as hypothetical cultural attractors and repellors within the role identity state-space. For example, for a high school student with a current "High School Student" role identity, a futureimagined role identity of a "knowledgeable college student" can constitute a self-related goal within the broader "Student" role identity, whereas a "college dropout" may constitute a futureimagined role identity to avoid.

Relative to current role identities, future-imagined role identities are likely to be thinner in content and more fragmented in structure. In trying to address a gap between stated future academic possible selves and actual academic pursuits among low-income and minority teens, Oyserman et al. (2006) intervened with middle-school students to link positive future-imagined academic possible selves (e.g., passing $8^{\text {th }}$ grade) and feared future-imagined possible selves (e.g., having to repeat $8^{\text {th }}$ grade; becoming involved in a gang) with particular contextually relevant 
strategies (action possibilities) for attaining the positive future-imagined role identities while emphasizing that such attainment is normatively difficult (ontological beliefs) and promoting congruence (integration) between these academic future-imagined possible selves and students' racial-ethnic social identities. Similarly, future-imagined role identities constitute a central feature in any professional training, where students or trainees (e.g., student-teachers) occupy a current "Student" role identity tasked with constructing a future-imagined "Professional" role identity (e.g., a teacher; Nolen, Ward \& Horn, 2011). The inherent task of professional training is to support participants who are occupying the "Student" role identity in constructing a futureimagined "Professional" role identity that would serve as a strong foundation for the construction of a current "Professional" role identity when the time comes to actually occupy that role.

\section{The Contribution of the DSMRI to the Identity Literature}

The prominent statistician George E. P. Box argued that "[e]ssentially, all models are wrong; but some are useful" (Box \& Draper, 1987, p. 424). Like any other theoretical model, the DSMRI does not purport to be "true," or to capture well all identity phenomena. The model aims to address certain challenges in the current identity literature, and to be useful to researchers and practitioners who are interested in understanding, investigating, and intervening in identity processes. Arguably, current models of identity and its development from different perspectives seem to have complementary but distinct strengths. Exceptions notwithstanding (e.g., Burke \& Stets, 2009), some models can be said to be particularly informative about the role of structural features of the individual's overall Identity and the generalized processes of its formation in people's actions and well-being, but less so regarding the role of the content of those Identities (e.g., Identity statuses; Marcia, 1993). Other models are particularly informative regarding specific content of elements in domain-based identities, such as particular self-perceptions in a domain or task (e.g., Bandura, 1997), values regarding a domain (e.g., Eccles, 2009), or self-related goals or strategies (Berzonsky, 1989; Kaplan \& Flum, 2010), but may attend less to the rich and dynamic nature of identity processes. And yet other models focus primarily on the holistic, contextualized, and rich identity content and processes of identity formation (e.g., Holland et al., 1998), but lack a 
systematic set of concepts that may afford direct integration of findings from studies conducted in different contexts and with different people. In comparison, the DSMRI reflects the holistic, contextualized, dynamic, varied, and rich nature of the role identity, while at the same time, anchoring it in central constructs from the established motivational, self, and identity literatures. It does so by manifesting the CDS assumptions of systemic unit-of-analysis, dynamic iterative change, and circular cause-effect paths (Witherington, 2015), and the Relational principles of interdependence, didactic distinctions, and synthesis to the whole (Overton, 2013). As such, the DSMRI is a meta-theoretical framework: it specifies a set of conceptual anchors and principles of operation that provide a framework and guides for systematic assessment, investigation, and intervention in identity phenomena. It does not, a priori, specify the particular content, structure, or process that would manifest in the identity system of particular individuals in a particular group in a particular context. It provides a conceptual starting point for researchers who can utilize the DSMRI to pursue broad research questions, concerning the general characteristics of the identity system and whether they are similar or different across levels, as well as to develop and test more specific theories concerning the identity content, structure, and process among individuals or groups with different characteristics and in different contexts (e.g., the nature of change in the role identity systems of novices as they develop into experts).

\section{Application of the DSMRI in Identity Research and Interventions}

The DSMRI provides a framework that guides identity scholars to consider: (1) the target for investigation or intervention as a particular role identity of a certain unit-of-analysis (e.g., a high school science teacher role identity), (2) the conceptual attractors in the cultural state-space of that role identity (e.g., student-centered teacher role identity), (3) the target content within the role identity (e.g., ontological beliefs about malleability of student ability, perceived action possibilities of inquiry pedagogical methods for teaching high school science), (4) the structure within the role identity system (e.g., extent of harmony, alignment between the components, and integration of the science teacher role identity with other salient role identities), and (5) the process and change in the role identity system (e.g., iterative changes in the teacher role identity 
system reflecting identity exploration of the meaning of adopting inquiry pedagogical methods into practice). The DSMRI also provides guides to the design of the identity data collection and of interventions (Kaplan \& Garner, 2016). First and foremost, the DSMRI calls for adopting the assumptions of CDS regarding the indeterminate, dynamic, iterative, nonlinear, culturalcontextual, and system-centered nature of identity and its change. As such, the optimal research design to evaluate the identity system and its change would be a comprehensive longitudinal case study that employs triangulation of data from multiple methods to characterize and follow the dynamics of the participant's identity system iterations. Such a comprehensive design is not always possible, or even necessary in order to pursue certain identity-related research questions. Yet, the assumptions regarding the iterative nature of the identity system change (e.g., initial identity states as a basis for future iterations), the tendency of the identity system to self-organize towards coherence and integration, and the adaptive process of identity exploration and selfconstruction, highlight the importance of designing studies that aim at the unit-of-analysis of the actor's role identity system in its context, and its change along time.

We highlight particularly the contribution of the DSMRI to conceptualizing and designing interventions in identity phenomena such as prompting role identity exploration in educational settings, professional development program, and counseling contexts. Generally, an underlying assumption of the CDS approach is that an intervention in a dynamic system is one force among many operating within and on the system, some more enduring and others short-lived, some that can be anticipated and others not, which integrate to influence the future iterations of the complex dynamic system. Thus, an intervention can be anticipated to exert an influence on the system in a particular direction, but not to completely determine its future states. However, the more familiar the intervention designers are with the content, structure, history, context, and control parameters that afford and constrain the processes in the target system, the higher could be their confidence about the anticipated influence of their intervention. In addition, the assumptions concerning the dynamics of the complex dynamic systems call for repeated evaluation of its features and adjustment of the intervention to coordinate its influence with the system's continuously emerging 
iterative states and shifting contexts, and according to the time scale of the system's iterations (Koopmans \& Stamovlasis, 2016). Therefore, from a CDS perspective, an effective approach to identity intervention studies would assume a design-based methodology, in which the implementation of activities and the investigation of their effects on the systems are continuous and cyclical (Fishman, Penuel, Allen, Cheng, \& Sabelli, 2013; Kaplan, Katz \& Flum, 2012). The DSMRI provides designers of identity interventions with a conceptual framework to evaluate the specific content and structure of the participant's initial state of role identity system, design activities that aim to facilitate particular identity formation processes perceived to be conducive to the goals of the program, and measure particular content, structure, and change processes in the target system in order to evaluate effectiveness of the intervention activities in achieving these goals, and to guide design of future activities. More specifically, the DSMRI can guide designers in mapping the content and structure of participants' target role-identity system - their ontological and epistemological beliefs, purpose and goals, self-perceptions and self-definitions, perceived action possibilities, their associated emotions and their relations. Beginning an intervention with such role identity system mapping can serve both familiarizing the intervention designers and facilitators with participants' initial role identity systems and highlighting potential foci for identity construction activities (e.g., facilitating identity exploration of content of certain components and their relations) as well as eliciting participants' awareness to and reflection on their role identity in ways that could promote their readiness to engage in such identity construction. In turn, the DSMRI can guide evaluation of the nature of the role identity formation processes, and the change in content and structure of participants' role identity in response to the interventions. Importantly, the DSMRI highlights the unit-of-analysis of the actor-whether an individual or a collective - and emphasizes the assumption that any particular activity cannot be expected to manifest identical change processes across participants' role identity systems, or in the same actor's identity system at different contexts and time. However, it provides conceptual tools to discern possible reasons for such variation. 
In the past several years, together with different colleagues, we have applied the DSMRI in number of research projects. For example, in the context of a certificate program in Teaching in Higher Education for graduate students at a research university, we employed the DSMRI as a framework for coding and evaluating change in teaching philosophy statements that the 15 participants wrote at the beginning and at the end of the program (Gunersel, Kaplan, Barnett, Etienne \& Ponnock, 2016). The analysis characterized the state (content and structure) of each participant's teacher role identity system at the beginning and at the end of the program, as well as the overall change in each participant's role identity. Comparing and contrasting the teaching role identity change among the 15 cases, we identified three general patterns which we labeled "transformation," "elaboration," and "stagnation." The analysis also provided conceptual insights regarding the characteristics of graduate students' initial teaching role identity system that may be anticipated to respond to the certificate program with a certain pattern of change. A similar design was used in a pre-mid-post interview study of five teachers who participated in an eight-day teacher professional development (PD) program, with analyses characterizing the content and structure of each participant's role identity system at the three time points, with post-hoc interpretation concerning the nature of identity processes and change taking place in each participant's identity system (Hathcock, 2014). Importantly, the analysis in such designs maintains the unit-of-analysis of the individual participant's role identity. However, such study design is limited by capturing the identity system states only at two or three time points, and its change post-hoc, thus providing only a general and imprecise depiction of the participants' identity processes and change. A more robust design that aims to investigate the effect of a program on participants' role identity system would include more frequent measures, as well as capturing the iterative states of the role identity system following specific program activities that aim to influence the role identity system in a particular direction.

We employed a more frequent assessment of participants' teaching role identity in the evaluation of change in the role identity system of high school science teachers who participated in an eight-day (PD) summer institute (Garner, Kaplan, Hathcock \& Davidson, 2013; St. Pierre \& 
Halpern, 2016). In this study, each participant completed daily brief surveys and daily open-ended writing in response to prompts asking about meaningful experiences during the day in the PD and the relevance of these experiences to teaching in the classroom. Analysis of the content and structure of each participant's eight daily entries characterized the participant's role identity system and its pattern of change along the professional development, and in response to specific program activities each day. The facilitators of the professional development institute relied on participants' reflective writing each day to evaluate the dynamic change in each participant's role identity and to consider modifications to the following day's activity in ways that take into account the history of the participants' role identity systems and attempt to influence their next iteration along the PD goals. Other projects that took a similar approach involved an investigation of the teaching role identity change of a first year teacher through a DSMRI analysis of the teacher's weekly diary entries (Veder-Weiss \& Biran, 2016), evaluation of an intervention in preservice elementary school teachers' mathematics student role identity and its transfer to futureimagined teacher role identity in an undergraduate mathematics course through DSMRI-structured prompts delivered each class for the duration of the semester (Heffernan, 2016), evaluation of an intervention in high school students' mathematics student role identity in an Algebra II course through DSMRI-structured prompts delivered during each class during a semester (Peterson, 2016), and an investigation of undergraduate students' biology student role identity through DSMRI-guided surveys delivered weekly throughout the semester. ${ }^{2}$ Importantly, decisions about the measure of the role identity system and the frequency of data collection should correspond to the role identity targeted, the research question about that role identity, and assumptions about the time scale of its meaningful iterative change (e.g., seconds, minutes, hours, days, weeks, years).

\section{Conclusion}

The Dynamic Systems Model of Role Identity (DSMRI) provides a conceptual framework that integrates insights from several contemporary identity perspectives that commonly are considered to uphold incompatible ontological and epistemological assumptions about identity and its development. Adopting assumptions from the Complex Dynamic Systems approach, which 
correspond with those of the Relational-Developmental Systems Paradigm, the DSMRI provides a meta-theoretical framework that allows the conceptualization of identity phenomena that manifest stability and change, personal and social-cultural mechanisms, and conscious and implicit influences. It further affords such conceptualization at different units-of-analysis, ranging from a very specific act-based role, to social identities, to the overarching psychosocial individual Identity, and even to the identities of collectives such as teams and organizations.

Research and intervention work that uses the DSMRI as a guiding theoretical framework is currently underway in variety of domains and contexts, including in professional development of novice and veteran teachers in the US and in Israel; pre-service teachers in mathematics and mathematics high school students in the US; Jewish and Arab school counselors in training in Israel; occupational therapy professional education in Israel; Jewish and Arab community leaders' training in Israel; and Israeli high school students' collaborative academic decision making (Kaplan \& Garner, 2016). This work pursues the scholarly project of investigating the validity and utility of the DSMRI's assumptions and specifications for understanding and characterizing diverse identity phenomena. Clearly, many questions remain concerning the highly complex facets of the complex dynamic systems that may capture such different identity phenomena (cf. Bar Yam, 1992). Research is required that investigates the content that serves as conceptual cultural attractors for particular role identities in certain contexts. Current literatures on these role identities could provide starting points for identifying such attractors (e.g., student role identities as learning-oriented and performance-oriented; teacher role identities as teacher-centered and student-centered; parent role identities as authoritative, authoritarian, and permissive; leader role identities as transactional and transformational). Research is also needed to characterize the structural and process characteristics of complex dynamic systems that may best capture diverse identity phenomena. For example, do emergent properties of different identity phenomena at different units-of-analysis and time scales manifest enhanced or decreased complexity? What is the nature of the interplay among the various role identity components in the emergence of action, and how does this interplay differ among role identities that manifest different control 
parameters - for example, among people with different implicit dispositions? What is the nature of the vertical circular causality between more specific and more general units-of-analysis within the identity system? Such questions reflect the great complexity of the identity system and how much still needs to be understood. Yet, it is frameworks, such as the DSMRI, which rely on assumptions specified by the growing field of complex dynamic systems, that allow phrasing such questions and pursuing them in a systematic and epistemologically coherent way. It is this work that promises to greatly enhance our understanding of identity phenomena and our ability to intervene to promote adaptive identities and wellbeing. 


\section{Endnotes}

${ }^{1}$ Since most of our work has been undertaken in educational contexts, our examples reflect these contexts. However, we believe that the DSMRI can be applied generally.

${ }^{2}$ Interested researchers may contact the authors for methodological materials, including prompts for reflective identity writing, interview protocols, brief identity prompts, and a manual and codebooks for analytical procedures based on the DSMRI. 


\section{References}

Bandura, A. (1997). Self-efficacy: The exercise of control. NY: Freeman.

Bar-Yam, Y. (1997). Dynamics of complex systems. NY: Perseus Press.

Berzonsky, M. D. (1990). Self-construction over the life-span: A process perspective on identity formation. In G. J. Neimeyer, \& R. A. Neimeyer (Eds.), Advances in personal construct theory (pp. 155-186). Greenwich, CT: JAI Press.

Boekaerts, M. (2010). Motivation and self-regulation: Two close friends. In The decade ahead: Applications and contexts of motivation and achievement; Advances in motivation and achievement (Vol. 16, pp. 69-108). Emerald Group Publishing.

Boekaerts, P. R. Pintrich, \& M. Zeidner (Eds.) (2000). Handbook of self-regulation. San Diego, CA: Academic Press.

Bosma, H., A., \& Kunnen, E. S. (2001). Determinants and mechanisms in identity development: A review and synthesis. Developmental Review, 21, 39-66.

http://dx.doi.org/10.1006/drev.2000.0514

Box, G. E. P., \& Draper, N. R. (1987). Empirical model building and response surfaces. New York, NY: John Wiley \& Sons.

Bruner, J. (1990). Acts of meaning. Harvard University Press.

Burke, P. J., \& Stets, J. E. (2009). Identity theory. Oxford University Press.

Côté, J. E., \& Levine, C. (2002). Identity formation, agency, and culture: A social psychological synthesis. Mahwah, NJ: Lawrence Erlbaum Associates.

Dweck, C. S. (1999). Self-theories: Their role in personality motivation and development. Academic Press.

Dweck, C. S. (2006). Mindset. NY: Balantine Books.

Eccles, J. (2009). Who am I and what am I going to do with my life? Personal and collective identities as motivators of action. Educational Psychologist, 44(2), 78-89. http://dx.doi.org/10.1080/00461520902832368

Erikson, E. H. (1968). Identity. Norton. 
Fishbein, M., \& Ajzen, I. (2011). Predicting and changing behavior: The reasoned action approach. Taylor \& Francis.

Fishman, B. J., Penuel, W. R., Allen, A. R., Cheng, B. H., \& Sabelli, N. O. R. A. (2013). Designbased implementation research: An emerging model for transforming the relationship of research and practice. National Society for the Study of Education, 112(2), 136-156.

Flum, H. (1994). The evolutive style of identity formation. Journal of youth and adolescence, 23(4), 489-498.

Flum, H., \& Kaplan, A. (2006). Exploratory orientation as an educational goal. Educational Psychologist, 41, 99-110.

Garner, J. K., Kaplan, A., Hathcock, S., \& Davidson, Y. (2013, May). A complexity science approach to identity formation: Demonstration with data from teacher professional development. Poster presented at the $25^{\text {th }}$ annual convention of the Association for Psychological Science, Washington DC.

Gergen, K. (1991). The saturated self: Dilemmas of identity in contemporary life. Basic books. Grotevant, H.D. (1987). Toward a process model of identity formation. Journal of Adolescent Research, 2(3), 203-222.

Guastello, S. J., Koopmans, M., \& Pincus, D. (2009). Chaos and complexity in psychology. Cambridge, Cambridge University.

Guastello, S. J., \& Liebovitch, L. S. (2009). Introduction to nonlinear dynamics and complexity. In Guastello, S. J., Koopmans, M., \& Pincus, D. (Eds.). Chaos and complexity in psychology. Cambridge: Cambridge University.

Gunersel, A. B., Kaplan, A., Barnett, P., Etienne, M., \& Ponnock, A. R. (2016). Profiles of change in motivation for teaching in higher education at an American research university. Teaching in Higher Education, 21(6), 628-643. DOI: $10.1080 / 13562517.2016 .1163668$ 
Hamaker, E. L. (2012). Why researchers should think "within-person": A paradigmatic rationale. In M. R. Mehl \& T. S. Conner (Eds.), Handbook of research methods for studying everyday life (Ch. 3, pp. 43-61). New York: Guilford.

Hathcock, S. (2014). Professional identity and pedagogical discontentment in high school science teachers participating in a professional development institute. (Unpublished doctoral dissertation). Institution and Location redacted.

Hattie, J. (2014). Self-concept. Psychology Press.

Heffernan, K. (2016). Promoting preservice teachers' mathematics identity exploration (Unpublished doctoral dissertation). Institution and Location redacted.

Hofer, B. K., \& Pintrich, P. R. (2004). Personal epistemology: The psychology of beliefs about knowledge and knowing. Psychology Press.

Holland, D., \& Lachicotte, W. (2007). Vygotsky, Mead, and the new sociocultural studies of identity. The Cambridge companion to Vygotsky, 101-135.

Holland, D., \& Lachicotte, Jr., W., Skinner, D., \& Caine, C. (1998). Identity and agency in cultural worlds. Harvard College.

Kaplan, A. \& Garner, J. K. (2016, April). Teacher identity and motivation: Concepts, research designs, and empirical examples. Symposium presented at the annual convention of the American Educational Research Association, Washington DC, USA.

Kaplan, A., \& Maehr, M. L. (2002). Adolescents' achievement goals: Situating motivation in socio-cultural contexts. In F. Pajares \& T. Urdan (Eds.), Adolescence and education: Vol. 2, Academic motivation of adolescents (pp. 125-167). Greenwich, CT: Information Age.

Kaplan, A., Sinai, M., \& Flum, H. (2014). Design-based interventions for promoting students’ identity exploration within the school curriculum. In S. Karabenick \& T. Urdan (Eds.) Advances in motivation and achievement (Vol. 18; pp. 247-295). Emerald Group. Authors

Kelso, J. A. S. (1995). Dynamic patterns: The self-organization of brain and behavior. Cambridge, MA: MIT Press. 
Kunnen, S. (Ed.) (2012a), A dynamic systems approach to adolescent development. London, UK: Routledge/Psychology Press.

Kunnen, S. (2012b). The art of building dynamic systems models. In S. Kunnen (Ed.), A dynamic systems approach to adolescent development (pp. 99-116). London, UK:

Routledge/Psychology Press.

Kunnen, S., \& Van Geert, P. (2012). A dynamic system approach to adolescent development. In S. Kunnen (Ed.), A dynamic systems approach to adolescent development (pp. 3-14). London, UK: Routledge/Psychology Press.

Lerner, R. M. (2012). Developmental science: Past, present and future. International Journal of Developmental Science, 6, 29-36. DOI: 10.3233/DEV-2012-12102

Locke, E. A., \& Latham, G. P. (2002). Building a practically useful theory of goal setting and task motivation: A 35-year odyssey. American psychologist, 57(9), 705. http://dx.doi.org/10.1037/0003-066X.57.9.705

Luyckx, K., Goossens, L., Soenens, B., \& Beyers, W. (2006). Unpacking commitment and exploration: Preliminary validation of an integrative model of late adolescent identity formation. Journal of adolescence, 29(3), 361-378.

http://dx.doi.org/10.1016/j.adolescence.2005.03.008

Maehr, M. L. (1984). Meaning and motivation: Toward a theory of personal investment. In C. Ames \& R. Ames (Eds.), Research on motivation in education, (Vol. 1, Ch. 4, pp. 115144). Academic Press.

Maehr, M. L., \& Braskamp, L. A. (1986). The motivation factor: A theory of personal investment. Lexington, MA: Lexington Books.

Maehr, M. L., \& McInerney, D. M. (2004). Motivation as personal investment. In D. M. McInerney \& S. Van Etten (Eds.), Big theories revisited (pp. 61-90). Greenwich, CT: Information Age. 
Marcia, J. E. (1993). The ego identity status approach to ego identity. In J. E. Marcia, A. S. Waterman, D. R. Matteson, S. L. Archer and J. L. Orlofsky (Eds), Ego identity: A handbook for psychosocial research (pp. 3-21). New York: Springer-Verlag.

Markus, H., \& Nurius, P. (1986). Possible selves. American Psychologist, 41(9), 954. http://dx.doi.org/10.1037/0003-066X.41.9.954

Nolen, S. B., Horn, I. S., Ward, C. J., \& Childers, S. A. (2011). Novice teacher learning and motivation across contexts: Assessment tools as boundary objects. Cognition and Instruction, 29(1), 88-122. http://dx.doi.org/10.1080/07370008.2010.533221

Overton, W. F. (2013). A new paradigm for developmental science: Relationism and relationaldevelopmental systems. Applied Developmental Science, 17(2), 94-107. http://dx.doi.org/10.1080/10888691.2013.778717

Oyserman, D., Bybee, D., \& Terry, K. (2006). Possible selves and academic outcomes: How and when possible selves impel action. Journal of personality and social psychology, 91(1), 188-204. http://dx.doi.org/10.1037/0022-3514.91.1.188

Penuel, W. R., \& Wertsch, J. V. (1995). Vygotsky and identity formation: A sociocultural approach. Educational psychologist, 30(2), 83-92. http://dx.doi.org/10.1207/s15326985ep3002_5

Peterson, S. (2016). An intervention for promoting student identity exploration, motivation, and achievement in high school mathematics classrooms. (Unpublished doctoral dissertation). Institution and Location redacted.

Rowland, G. (2007). The challenge of new science. Performance Improvement Quarterly, 20, 920. DOI: 10.1111/j.1937-8327.2007.tb00437.x

Schwartz, S. J., Luyckx, K., \& Vignoles, V. L. (2011). Handbook of identity theory and research. New York, NY: Springer-Verlag.

Sinai, M., Tossman, I., \& Kaplan A. (2016, August). Professional identity formation and motivation of the school counselors: A case study. Paper presented at the biennial meeting of the International Conference on Motivation, Thessaloniki, Greece. 
St. Pierre, M., \& Halpern, M. (2016, August). Science teachers' identity processes in the context of professional development: A diary study. Poster presented at the annual convention of the American Educational Research Association, Washington DC, USA.

Turner, J. C., \& Reynolds, K. J. (2011). Self-categorization theory. In P. A. M. Van Lange, A. W. Kruglanski \& E. T. Higgins (Eds.) Handbook of theories of social psychology (pp. 399417). Sage.

van Geert, P., \& Steenbeek, H. (2005). Explaining after by before: Basic aspects of a dynamic systems approach to the study of development. Developmental Review, 25, 408-442. DOI: 10.1016/j.dr.2005.10.003

Vansteenkiste, M., Lens, W., \& Deci, E. L. (2006). Intrinsic versus extrinsic goal contents in selfdetermination theory: Another look at the quality of academic motivation. Educational psychologist, 41(1), 19-31. http://dx.doi.org/10.1207/s15326985ep4101_4

Veder-Weiss, D., \& Biran, L. (2016, April). Change in one teacher's professional identity during the first year of teaching in an alternative school: A case study. Poster presented at the annual convention of the American Educational Research Association, Washington DC, USA.

Vignoles, V. L., Schwartz, S., J., \& Luyckx, K. (2011). Introduction: Toward an Integrative View of Identity. In Schwartz, S. J., Luyckx, K., \& Vignoles, V. L. (Eds.). Handbook of identity theory and research (pp. 1-27). New York, NY: Springer-Verlag.

Waldrop, M. M. (1992). Complexity: The emerging science at the edge of order and chaos. New York, NY: Touchstone.

Weiner, B. (2012). An attribution theory of motivation. Handbook of theories of social psychology, 1, 135-155.

Witherington, D. C. (2007). The dynamic systems approach as metatheory for developmental psychology. Human Development, 50(2-3), 127-153. DOI:10.1159/000100943

Witherington, D. C. (2015). Dynamic systems in developmental science. In R. Lerner (Ed.), Handbook of Child Psychology and Developmental Science (7th Ed., Ch. 3). John Wiley. 
Identity as a Complex Dynamic System

Zimmerman, B. J. (2008). Investigating self-regulation and motivation: Historical background, methodological developments, and future prospects. American Educational Research Journal, 45(1), 166-183. DOI: 10.3102/0002831207312909

Zusho, A., \& Clayton, K. (2011): Culturalizing Achievement Goal Theory and Research, Educational Psychologist, 46(4), 239-260. DOI: 10.1080/00461520.2011.614526 
Figure 1

The Dynamic Systems Model of Role Identity

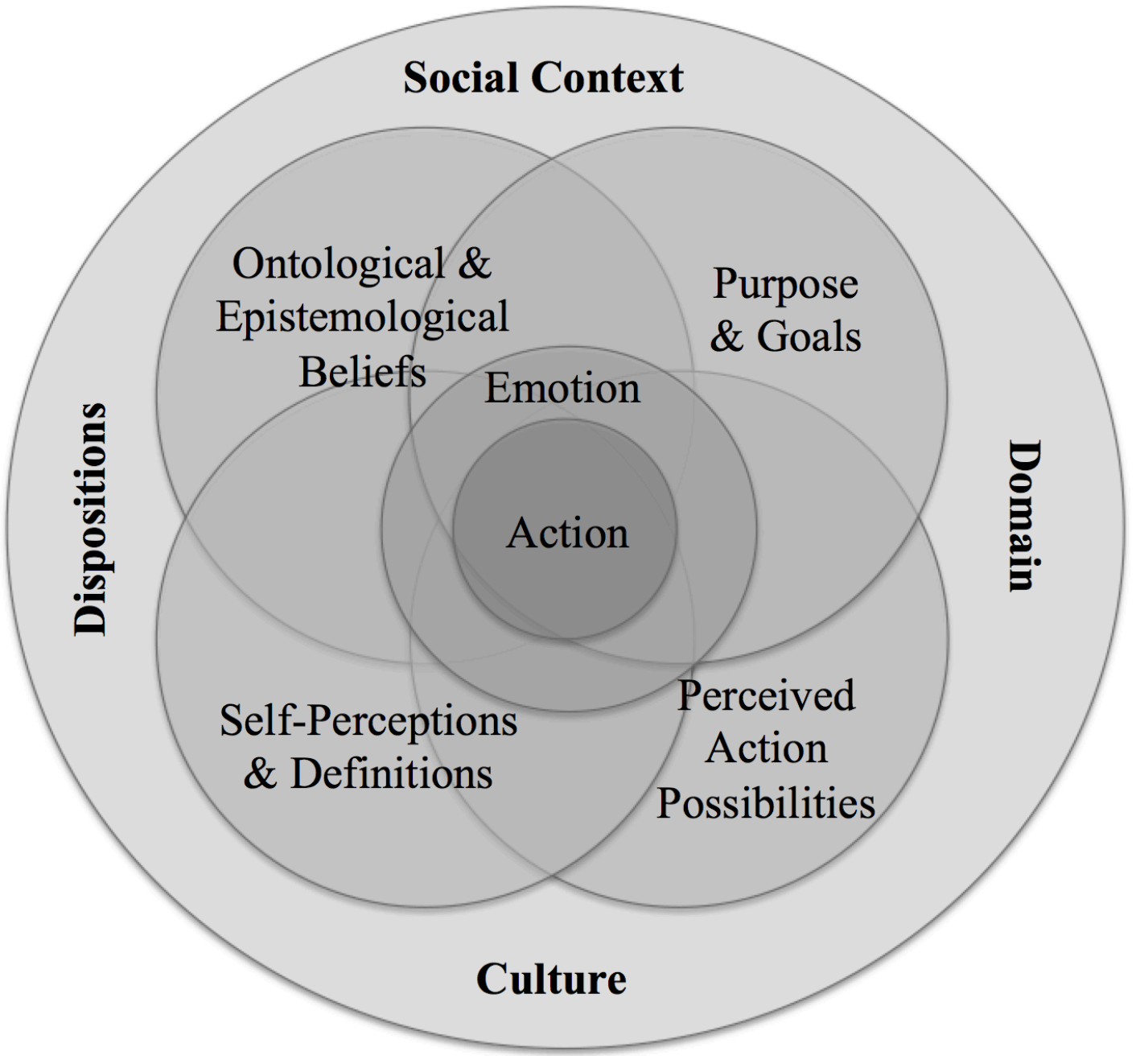


Identity as a Complex Dynamic System

Figure 2

The Hierarchical self-similarity structure of the Dynamic Systems Model of Role Identity

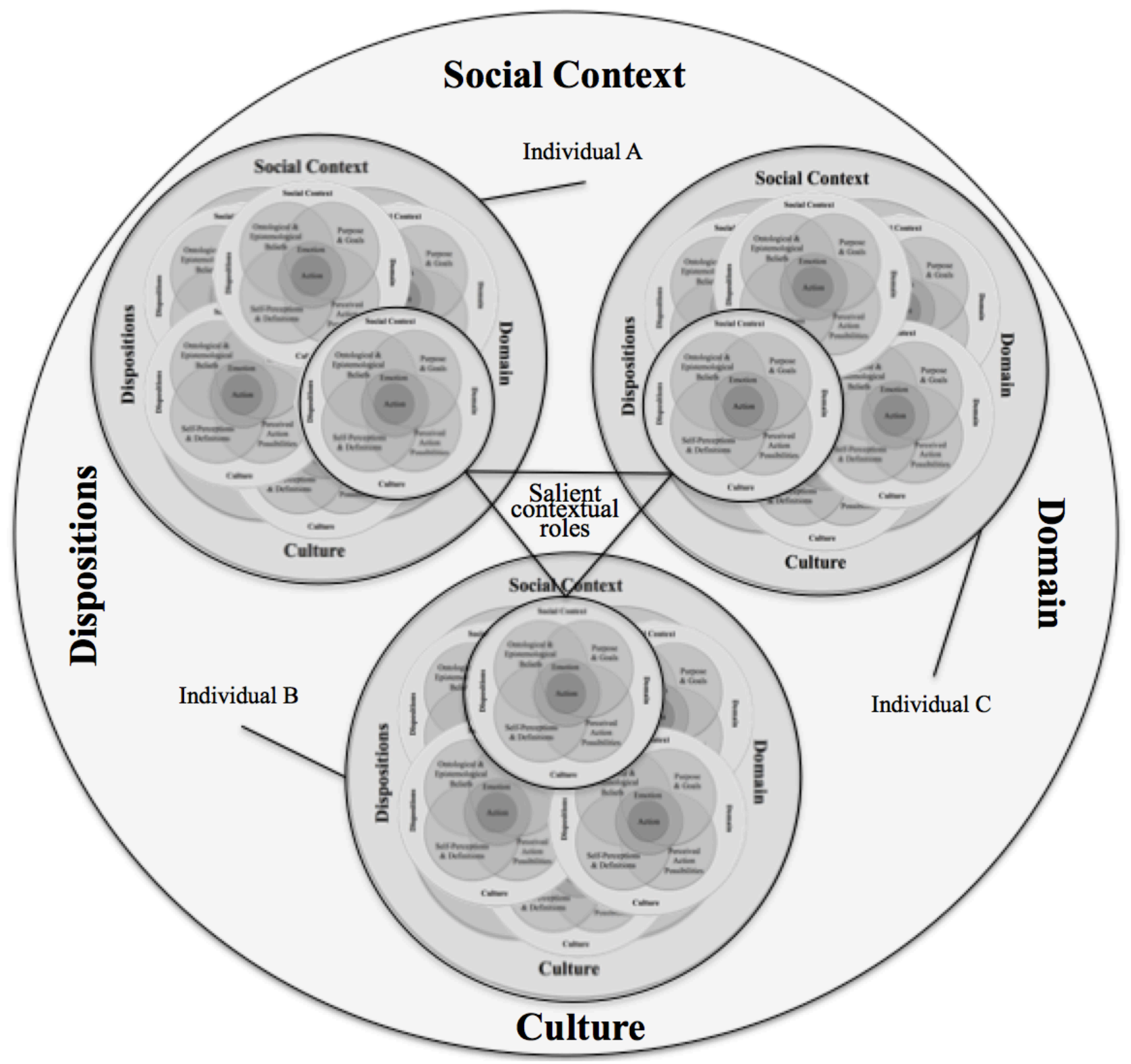

